\title{
Diurnal variation of the human auditory evoked potential
}

\author{
CARL P. BROWMAN \\ Rush-Presbyterian-St. Luke's Medical Center, Chicago, Illinois 60612
}

\begin{abstract}
Averaged auditory evoked potential (AEP) waveforms were computed during morning and evening sessions from human bipolar scalp recordings. Pure-tone stimuli were presented binaurally at 10 intensity levels at each time of day. Linear amplitude-intensity functions were obtained at both sessions. There was no relative change in the amplitude-intensity function. The difference between residual variances at the two time periods and the difference between regression coefficients were nonsignificant. However, waveform amplitude significantly decreased during the evening. The results demonstrated a negative shift of the AEP amplitude-intensity function from morning to evening.
\end{abstract}

It is well established that an individual's physiological, psychological, and behavioral states vary throughout the waking hours (diurnal rhythms). Aschoff (1965) suggests that all functions in the body exhibit a daily periodicity. While time-of-day changes have been demonstrated for a number of sensory processes, it remains unclear if a diurnal variation exists for the human auditory evoked potential (AEP) waveform. Heninger, McDonald, Goff, and Sollberger (1969) and Tepas (1967) failed to observe significant changes in the AEP across time. It may be argued, however, that these studies collected AEPs under conditions which minimized apparent diurnal effects.

Tepas (1967) measured the AEP while subjects were maintained in confinement for $48 \mathrm{~h}$ on assigned schedules which ranged from 5-h alternating workrest periods to $2.0-\mathrm{h}$ alternating periods. Available evidence indicates that entrainment of biological rhythms may be closely related to a regular pattern of sleep and wakefulness as well as periodic environmental contingencies or Zeitgebers (Aschoff, Fatranska, \& Giedke, 1971; Kleitman \& Jackson, 1950; Taub \& Berger, 1973). Heninger et al. (1969) measured the AEP at 8:00 a.m. and 5:00 p.m., but apparently there was no control for sleep duration or wake-up time. Other research suggests that both prior sleep and present wakefulness may influence biorhythms (Horne \& Östberg, 1977; Rutenfranz, Aschoff, \& Mann, 1972; Taub \& Berger, 1976). Thus, the results of these two studies do not necessarily preclude a diurnal change in the AEP under normal, controlled conditions.

This investigation was conducted at St. Louis University and was supported, in part, by Research Grant 5 R01 OH 00395 from the National Institute of Occupational Safety and Health. Requests for reprints should be sent to Dr. Carl P. Browman, Sleep Disorder Service and Research Center, Rush-PresbyterianSt. Luke's Medical Center, 1753 West Congress Parkway, Chicago, Illinois 60612 .
The present investigation reexamined AEP periodicity using strategies aimed at reducing variability due to nondiurnal factors. AEPs to 10 levels of stimulus magnitude were obtained during morning and evening sessions. The resulting amplitude-intensity functions allowed assessment of AEP amplitude at each time of day and the relative diurnal sensitivity of the AEP in terms of variability and slope of the functions.

\section{METHOD}

\section{Auditory Stimuli}

Pure tones of $1 \mathrm{kHz}$ were presented binaurally at a $1 / \mathrm{sec}$ rate. The duration of the stimulation was $25 \mathrm{msec}$ with a rise-fall time of $10 \mathrm{msec}$. Ten intensities, ranging from 60 to $87 \mathrm{~dB}$ SL (re: $20 \mu \mathrm{N} / \mathrm{m}^{2}$ ) in steps of $3 \mathrm{~dB} \mathrm{SL}$, were used. Timing and attenuation of the auditory stimulation were controlled by Grason-Stadler Series 1200 modules. The tones were delivered through matched Telephonics TDH 39 earphones mounted in MX41/AR cushions and HD11B headset. The earphone SLs were calibrated with a Brüel and Kjaer Model 158 audiometer calibrator with an NBS 9A 6-cc acoustic coupler.

\section{EEG Recording and Waveform Analysis}

The EEG was recorded on a Grass Model 7 polygraph with a Model 7P5B preamplifier. The time constant was $.45 \mathrm{sec}$; the high-frequency response was limited to $500 \mathrm{~Hz}$. Bipolar recordings were made using Grass E5S electrodes placed at $\mathrm{Cz}$ and $\mathrm{Oz}$ (Jasper, 1958). A Beckman 16-mm biopotential electrode attached to the forehead served as ground. The AX08 analog input of the Digital Equipment Corporation LAB-8 computer system received the amplified EEG signal.

AEPs were computed on-line using the Advanced Averager program (DEC-LB-U18C-PB). The EEG was sampled at $1 \mathrm{kHz}$ for $511 \mathrm{msec}$. The digital values for each of the 511 time plots of the summed waveform computed on each trial were punched on tape during the intertrial interval. After all sessions were completed, the EEG waveforms from separate trials at each intensity level were averaged across sessions by subject at each time of day using the Average Potential Evaluation program (Tepas, Kress, \& Klingaman, 1975). The resulting AEP waveform for each subject represented the average EEG response to 800 stimulus presentations per intensity for both morning and evening sessions. AEP waveform analyses were made from digital printouts. Peak-topeak amplitude measures were made from N100 to P200, as these deflections have been defined by Davis (1976). 
A standard square wave of $10 \mu \mathrm{V}$ and $100 \mathrm{msec}$ was run through the system and averaged at each session, then summed across sessions. The appropriate digital values for this pulse provided a scale for waveform amplitude calibration.

\section{Subjects}

Two female and one male normal-hearing adults served as volunteers. Their mean age was 26.67 years. All subjects had at least two complete practice sessions prior to the start of their experimental sessions. Subjects had a wake-up time of 7:00 a.m. following $7.5 \mathrm{~h}$ (Subjects 1 and 2) or $8.0 \mathrm{~h}$ (Subject 3) of sleep. These times were constant for the duration of the study. The subjects abstained from food and beverage at least $1.5 \mathrm{~h}$ prior to any recording. Female subjects participated during the luteal phase of their menstrual cycle.

\section{Procedure}

Research approval was obtained from the St. Louis University Institutional Review Board, and all volunteers gave written informed consent prior to any participation. Each subject was tested twice daily on four occasions. The 1 st and 2 nd test days as well as the 3rd and 4th test days were contiguous for all subjects; an average of 4.33 days intervened the 2 nd and 3 rd test days. The morning session each day had a midpoint of 11:00 a.m. and the evening session had a 9:00 p.m. midpoint. A session consisted of 20 trials with 100 stimulus presentations of a single tone intensity occurring per trial. Each intensity was thus presented during two trials every session. The stimuli were presented according to a randomized design, with the only restriction that no particular intensity level be repeated on consecutive trials. A different sequence was used for each session with the subject not informed of the order. The subjects were instructed to attend to and covertly count the stimuli throughout every trial.

The subjects were tested in an electrically shielded, soundattenuated room. A small light was used for eye fixation during trials. Following the 10th trial of each session, the subject was given a break for $10 \mathrm{~min}$.

\section{Statistical Analysis}

Amplitude-intensity functions for the mean data of the three subjects at each time period were computed by the method of
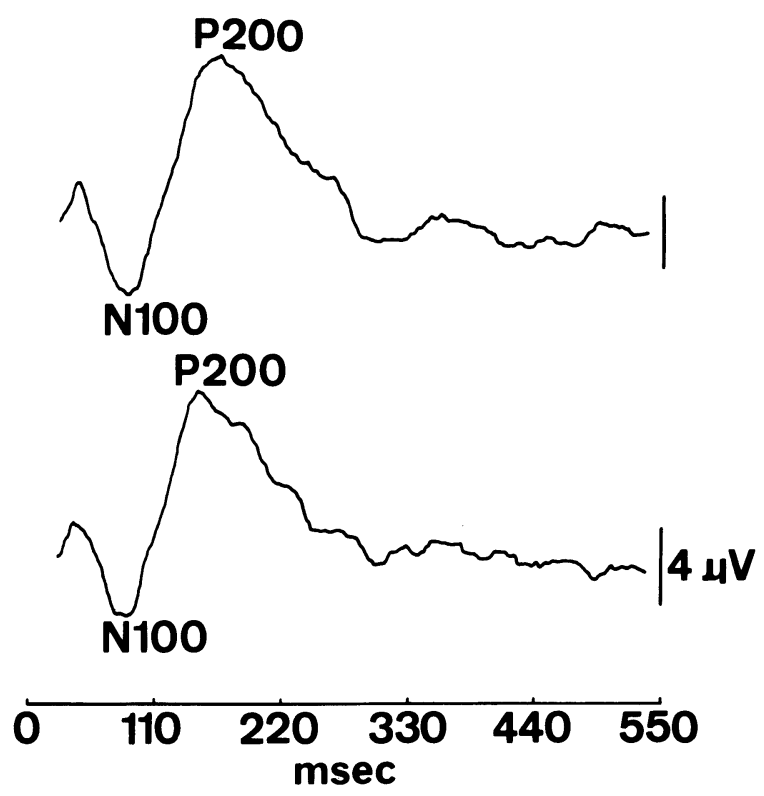

Figure 1. Morning (top) and evening waveforms to 69-dB SL stimulation for Subject 3. Downward deflection indicates that $\mathrm{Oz}$ was positive with respect to $\mathbf{C z}$.
Table 1

Regression Analyses

\begin{tabular}{lrrc}
\hline & Morning & Evening & \multicolumn{1}{c}{$F$} \\
\hline Standard Error of Estimate & .412 & .245 & 2.946 \\
Regression Coefficient $(\mu \mathrm{V} / \mathrm{dB}$ SL) & .066 & .054 & .459 \\
Mean Amplitude $(\mu \mathrm{V})$ & 11.350 & 10.870 & $22.745^{*}$ \\
\hline
\end{tabular}

${ }^{*} p<.002$.

least squares. The degree of variability was determined by standard errors of estimated AEP measures, and an F test $(\mathrm{df}=8,8)$ was used to compare residual variances of estimated amplitudes. Regression coefficients were calculated, and an $\mathrm{F}$ test $(\mathrm{df}=1,16)$ was used to compare the difference between morning and evening amplitude-intensity function slopes. An $F$ test $(\mathrm{df}=1,9)$ for repeated measures across obtained amplitude values was employed to assess time-of-day differences. The data entered in the calculation represented the obtained mean morning and evening amplitude values at each level of stimulus magnitude. This analysis assessed the difference in elevation between the amplitude-intensity functions at the two time epochs.

\section{RESULTS}

Representative waveforms from one subject are shown in Figure 1 with the N100 and P200 deflections identified. Peak-to-peak amplitude measurements represent the mathematical difference between these deflections.

The relationship between mean AEP amplitude and stimulus magnitude at both time periods can be described as a linear function over the intensity range examined (see Figure 2). The correlation coefficients between mean AEP amplitude measures for the three subjects and stimulus magnitude are .841 and .912 for the morning and evening sessions, respectively. Both coefficients are statistically significant (ps $<.01)$. The analyses of the amplitudeintensity functions are presented in Table 1 . There is no diurnal difference between residual variances and there is no difference between regression coefficients at the two sessions. Thus, there is no time-of-day variation in the relative amplitude-intensity relation. The change in mean AEP amplitude yields significant results $[\mathrm{F}(1,9)=22.745, \mathrm{p}<.002]$. On the average, AEP amplitude decreases $.48 \mu \mathrm{V}$ from morning to evening. AEPs early in the day at all levels of stimulus magnitude are greater in amplitude than corresponding evening AEPs.

All individual data exhibit this same relationship of greater AEP amplitude during the morning than during evening sessions. The change in amplitude averaged across stimulus magnitude is $.73 \mu \mathrm{V}$ for Subject $1, .14 \mu \mathrm{V}$ for Subject 2, and $.58 \mu \mathrm{V}$ for Subject 3.

\section{DISCUSSION}

The results of this study provide evidence for a previously unobserved diurnal variation of the AEP. 


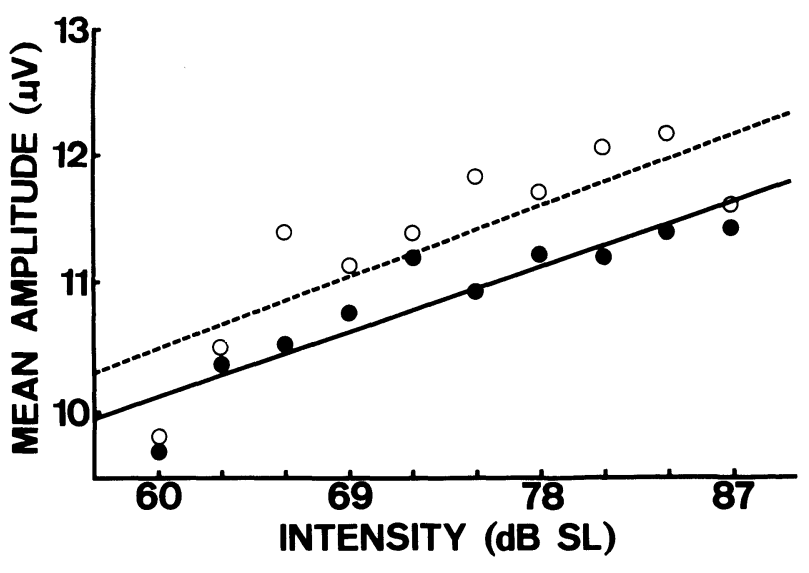

Figure 2. Mean AEP amplitude-intensity functions for morning (open circles and dashed line) and evening sessions. Amplitude measures represent the average response at each level of stimulus magnitude across subjects. Regression lines were fit to the data by the method of least squares.

It is demonstrated that AEP amplitude changes systematically with stimulus magnitude at both morning and evening sessions. Linear amplitude-intensity functions are obtained at each time of day which do not differ in terms of variability or slope. Using these two measures as an index of how sensitive the AEP is to changes in stimulus intensity (Klingaman \& Anch, 1972), the present results indicate a stability in the relative sensitivity of the AEP. The relative increase in AEP amplitude related to incremental changes in stimulus magnitude remains constant. However, there is a significant diurnal effect on the amplitude of the AEP. While relative sensitivity does not vary, AEP amplitude is attenuated from morning to evening. The function is lowered during the evening session without altering the basic amplitude-intensity relationship.

The present results show an amplitude difference at the two time periods examined. Although future research will need to determine the exact diurnal periodicity of the AEP by sampling at shorter time intervals throughout the day than sampled in this study, demonstrating a morning-evening change in amplitude is nonetheless an important first step.

If diurnal differences in the AEP are to be demonstrated, it is necessary that other sources of variability must be controlled. Precise control of stimulus parameters, subject attention levels, and sleep-wake times, as well as other strategies used in the present study, resulted in stable test conditions. Diurnal invariance due to such factors may produce the incorrect conclusion that the AEP does not exhibit a diurnal periodicity.

It is of interest to note that Tepas (1967) reported a clear rhythm for body temperature and Heninger et al. (1969) reported a time-of-day change for visual and somatosensory evoked responses. Neither study obtained a similar rhythm for the AEP. Weitzman and Luce (1969) point out that all biorhythms do not readapt at the same rate following disruptions to the wake-sleep regime. Additionally, the early-morning session in the Heninger et al. (1969) study may have included some carryover effect from sleep. Amplitude of the N100 and P200 deflections are generally suppressed during all stages of sleep relative to the waking state (Anch, 1977; Picton, Hillyard, Krausz, \& Galambos, 1974; Williams, Morlock, Morlock, \& Lubin, 1964; Williams, Tepas, \& Morlock, 1962). A full recovery to maximum amplitude immediately upon awakening would not necessarily be expected. Thus, the AEP appears to be more responsive to cyclic wake-sleep disruptions and "residual sleep effects" than other physiological measures.

A tentative hypothesis at this time is that the N100P200 component is related to physiological arousal. Arousal, as employed here, is a suitable hypothetical construct to explain time-course changes in an individual's level of wakefulness (see Tepas, 1967). N100-P200 amplitude is largest at midday, declines in the late evening, and, based on previous research, is at minimal levels during sleep. However, there are a number of issues involved in an attempt to relate the AEP to arousal; these have been discussed elsewhere (e.g., Callaway, 1975; Regan, 1972). In particular, the concept of arousal is too multidimensional to attribute to a single physiological measure. The AEP may reflect one aspect of arousal.

Clearly, it is important to control for time-of-day effects in AEP research. This is especially relevant to reliability studies and cases where comparisons are made following differential treatment.

\section{REFERENCES}

ANCH, M. The auditory evoked brain response during adult human sleep. Waking and Sleeping, 1977, 1, 189-194.

Aschoff, J. Circadian rhythms in man. Science, 1965, 148, 1427 1432.

Aschoff, J., Fatranska, M., \& Giedke, H. Human circadian rhythms in continuous darkness: Entrainment by social clues. Science, 1971, 171, 213-215.

Callaway, E. Brain electrical potentials and individual psychological differences. New York: Grune and Stratton, 1975.

DAvis, H. Electric response audiometry, with special reference to the vertex potential. In W. D. Neff \& W. D. Keidel (Eds.), Handbook of sensory physiology. New York: Springer-Verlag, 1976.

Heninger, G. R., McDonald, R. K., Goff, W. R., \& Sollberger, A. Diurnal variations in the cerebral evoked response and EEG: Relations to 17-hydroxycorticosteroid levels. Archives of Neurology, 1969, 21, 330-337.

Horne, J. A., \& Östberg, O. Individual differences in human circadian rhythms. Biological Psychology, 1977, 5, 179-190.

JASPER, H. The ten-twenty electrode system of the International Federation. Electroencephalography and Clinical Neurophysiology, 1958, 10, 371-375.

Kleitman, N., \& JACKson, D. P. Body temperature and per- 
formance under different routines. Journal of Applied Physiology, 1950, 3, 309-328.

Kingaman, R. L., \& ANCh, A. M. Human auditory evoked response intensity functions from monopolar and bipolar scalp recordings. Psychonomic Science, 1972, 29, 17-19.

Picton, T. W., Hillyard, S. A., Krausz, H. I., \& Galambos, R. Human auditory evoked potentials. I. Evaluation of components. Electroencephalography and Clinical Neurophysiology, 1974, 36, 179-190.

REGAN, D. Evoked potentials in psychology, sensory physiology, and clinical medicine. London: Chapman and Hall, 1972.

Rutenfranz, J., Aschoff, J., \& Mann, H. The effects of a cumulative sleep deficit, duration of preceding sleep period and body temperature on multiple choice reaction time. In W. P. Colquhoun (Ed.), Aspects of human efficiency: Diurnal rhythm and loss of sleep. London: English Universities Press, 1972.

TAub, J. M., \& Berger, R. J. Performance and mood following variations in the length and timing of sleep. Psychophysiology, 1973, 10, 559-570.

TAUB, J. M., \& BERGER, R. J. The effects of changing the phase and duration of sleep. Journal of Experimental Psychology: Human Perception and Performance, 1976, 2, 30-41.
TEPAS, D. I. Evoked brain response as a measure of human sleep and wakefulness. Aerospace Medicine, 1967, 38, 148-153.

Tepas, D. I., Kress, G., \& Klingaman, R. L. APE: Average potential evaluation software for the LAB-8 system. Behavior Research Methods \& Instrumentation, 1975, 7, 120-124.

Weitzman, E. D., \& Luce, G. Biological rhythms: Indices of pain, adrenal hormones, sleep, and sleep reversal. National Institute of Mental Health, Mental health program reports, No. 3. Washington, D.C: U.S. Government Printing Office, 1969.

Williams, H. L., Morlock, H. C., JR., Morlock, J. V., \& Lubin, A. Auditory evoked responses and the EEG stages of sleep. Annals of the New York Academy of Sciences, 1964, 112, 172-181.

Williams, H. L., Tepas, D. I., \& Morlock, H. C., JR. Evoked responses to clicks and electroencephalographic stages of sleep in man. Science, 1962, 138, 685-686.

(Received for publication February 15, 1979; revision accepted May $29,1979$. 